\title{
Numerical investigation on mechanical properties of a nanobiocomposite based on date palm fiber and nanoclays with interphase problem
}

\author{
Khaled Meliani, and Said Rechak
}

\begin{abstract}
The use of biocomposites has been a major concern in recent decades with the emergence of composites as materials that can replace conventional ones. To improve the mechanical properties of these materials, special attention is devoted to nano-reinforcements. Among these nano-reinforcements, NanoClays (NC) are attracting the attention of many researchers. This nanoparticle, in addition to being biobased, has good mechanical properties and its nanometric dimension allows it to be an interesting reinforcement for the composite because of the NC/Matrix surface contact that it develops. In this study, a 4-phase material (Matrix, NC, Palm fiber and interphase) will be studied and the effect of several parameters (Aspect Ratio (AR), distance between NC and loading point, interface thickness and interfacial conditions) will be assessed and discussed. To do this, a 3D FEM model is developed and a mesh convergence study is pre-established.
\end{abstract}

Keywords- nanobiocomposite, nanoclays, nanoparticle, nano-reinforcement, 4-phase material.

\begin{tabular}{ll} 
& \multicolumn{1}{c}{ NOMENCLATURE } \\
NC & NanoClays. \\
AR & Aspect Ratio. \\
RVE & Representative Volume Element. \\
FEM & Finite Element Method \\
BEM & Boundary Element Method \\
CNT & Carbon Nano Tube \\
ave & Average \\
ROM & Rule Of Mixtures \\
$\mathrm{t}_{\mathrm{i}}$ & Thickness of interphase
\end{tabular}

\section{INTRODUCTION}

The economic and environmental concerns associated with government initiatives have encouraged the search for more environmentally friendly alternatives to petroleum-derived composites.

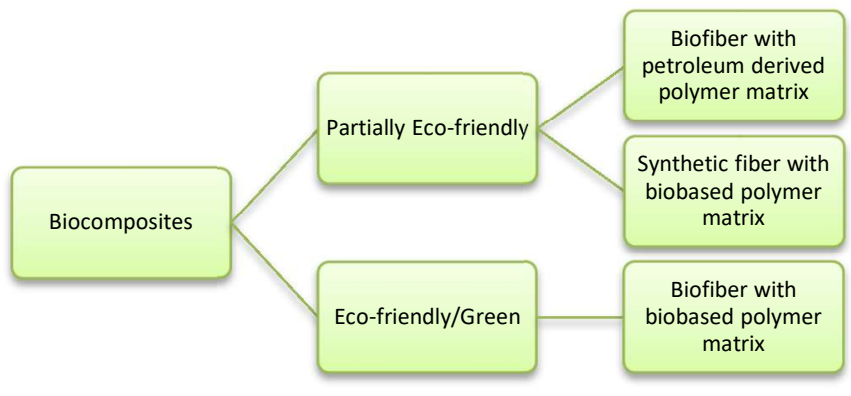

Fig. 1: Classification of biocomposites [1]

Manuscript received May 1, 2021; revised September 22, 2021

K. Meliani and S. Rechak are with the Mechanical Engineering and Development Laboratory, Department of Mechanical Engineering, Ecole Nationale Polytechnique, Algiers, ALGERIA.

(e-mail: khaled.meliani@g.enp.edu.dz, said.rechak@g.enp.edu.dz)
Much of this research has focused on the development of biocomposites and other renewable natural materials. Biocomposites can be broadly defined as a composite material that uses one or more environmentally friendly materials such as natural fiber reinforcements or biopolymers. (Fig. 1).

Recently, a large window of opportunity has opened up to overcome the limitations of traditional polymer composites at the micrometer scale by charged polymer composites at the nanoscale - in which the charge is $<100 \mathrm{~nm}$ in at least one dimension Fig. 2. Researchers have even studied a nano-biocomposite based on a natural fiber (date palm fiber) and carbon nanotubes 'CNT"' [2].

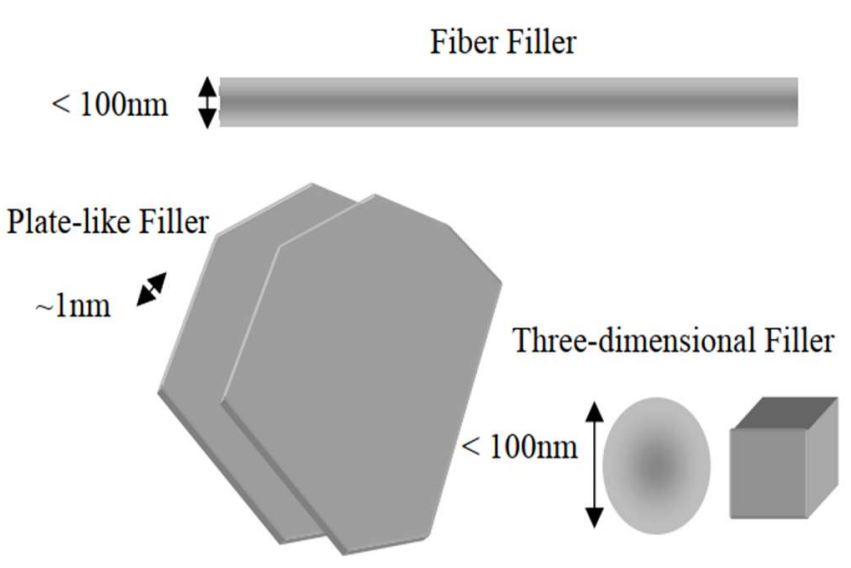

Fig. 2: Schematic of nano-scale filler [1]

Although some nanofilled composites (polymers charged with carbon black [3] and fumed silica [4, 5]) have been in use for more than a century, research and development of polymers has increased considerably in recent years, for several reasons. 
First, unprecedented combinations of properties have been observed in some polymer nanocomposites [6]. For example, the inclusion of equi-centered nanoparticles in thermoplastics, and in particular in semi-crystalline thermoplastics, increases the yield strength, tensile strength and Young's modulus [7] compared to pure polymer. A volume fraction of only 0.04 mica-type silicates (MTS) in the epoxy increases the modulus under the glass transition temperature by $58 \%$ and the modulus in the rubbery region by $450 \%$ [8]. In addition [9], the permeability of water in poly (e-caprolactone) decreases with the addition of $4.8 \%$ silicate. Yano et al. [10] showed a $50 \%$ decrease in the permeability of polyimides at a load of $2 \%$ MTS.

The "discovery" of carbon nanotubes in the early 1990s [11] is a second reason for the sharp increase in research and development efforts. Although closer examination has shown that nanotubes have been observed since the 1960s [12], it was not until the mid-1990s that they were manufactured in the quantities required for the evaluation of composite's properties. The properties of these carbon nanotubes, in particular resistance and electrical properties, are very different from those of graphite and offer interesting possibilities for new composite materials.

Third, a significant development in the chemical treatment of nanoparticles and in the in situ treatment of nanocomposites has led to unprecedented control of the morphology of these composites. It also created an almost unlimited ability to control the interface between the matrix and the filler.

Nanoclays are the good example of natural nanomaterials and are generally used for a clay mineral having a phyllosilicate or foil structure with a thickness of about $1 \mathrm{~nm}$ and areas of about 50 to $150 \mathrm{~nm}$ in one dimension [13, 14]. Nanoclays are therefore the general term for the layered mineral silicate nanoparticles having a high aspect ratio. Depending on the morphology of the nanoparticles and the chemical composition of the nanoclays are organized into various classes such as illite, halloysite, bentonite, kaolinite, montmorillonite, hectorite and chlorite [14]. Researchers explored that nanoclays can be obtained from raw clay minerals in fewer steps [15], instead of several general nanoparticle synthesis techniques [15].

The layered structure allows the material to swell or shrink depending on its tendency to absorb water. In addition, the purity and cation exchange capacity of nanoclay is one of the critical properties, as it provides the surface activity required for inclusion of modifiers and for surface treatments [16].

Nanoclays products are typically modified with ammonium salts and are often referred to as "organically modified nanoclays or organoclays" [17].

Organoclays are one of the attractive and promising inorganic organic hybrids of nanomaterials typically used for the modification of polymers and polymer-based composites. The modification of clay surfaces makes them organophilic to make them compatible with the hydrophobic properties of organic polymers [18].

The researchers stated that the structure of nanoclays or its dispersion in resins are of different types and can be characterized as separate, intercalated or exfoliated phases shown in Fig. 3 [19].

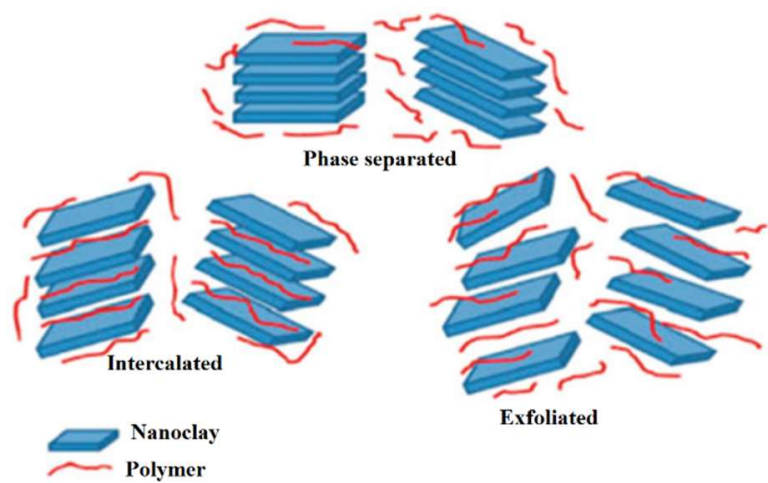

Fig. 3: Dispersion mechanism of nanoclay in resin.

In order to predict effective elastic properties, analytical methods (such as Mori and Tanaka, Halpin and Tsai, selfconsistent techniques) and numerical (homogenization technique based on representative volume element and finite element method) are often preferred to experimental approaches. During the last decade, several works have used various techniques to model nano-clay / polymer composites. Fornes and Paul [20] obtained the properties of the nylon - clay composite using the theory of composites. Luo and Daniel [21] characterize the mechanical behavior of the polymer / clay nanocomposite using the Mori-Tanaka Method for a threephase material. Odegard et al. [22] have also obtained the mechanical properties of nanoparticle polymer composites using a continuum-based micromechanics model. Hbaieb et al. [23] obtained the stiffness of the polymer / clay nanocomposite, they show prove that the Mori-Tanaka method is more accurate for aligned particles volume fractions less than $5 \%$. More recently, Wang et al. [24] presented the prediction and improvement of the tensile and breaking strength of epoxy / nanocomposite clay using a double interpenetrating network. Wang et al. [25] used a 3-D finite element model to obtain the elastic properties of a nano-reinforced polymer composite. Chia et al. [26] presented a 3-D finite element method to understand the effect of nanoparticles on the mechanical properties of epoxy clay nanocomposite using representative volume element (RVE). Zhu and Narh [27] used a numerical simulation to obtain the tensile modulus of a nano clay / polymer composite. Dong and Bhattacharyya [28] proposed a representative volume element (RVE) to find the mechanical behavior of a polymer / clay composite.

In the present study, a 3D FEM model is developed for the analysis of the bionanocomposite. The 'nanocomposite' is modeled with 3 and 4 phases (Matrix, palm fiber, NC and interphase) material. A first study on the convergence of the mesh as a function of the number of elements will be established. Then the effects of Aspect Ration ' AR', distance between NC itself, distance between NC and loading point, thickness of the interface, and the interfacial conditions will be evaluated and discussed.

\section{CONTINUUM MODELING APPROACH}

To predict the mechanical behavior of polymer nanocomposites, many modeling techniques are proposed, these modeling methods span a wide range of length and time scales. Computational chemistry are used for small length and time scales. However, computational mechanics is used to predict mechanical behavior of materials for largest length and time scales [29]. 
Continuum models are used for the analysis of a bio composite reinforced with date palm fiber and Nano Clay. The continuum based methods include, for computational micromechanics, the Finite Element Method (FEM) and the Boundary Element Method (BEM), and for analytical micromechanics it includes the Eshelby, Halpin-Tsai and Rule of mixtures approaches.

To extract the effective material properties of nanocomposites, both the analytical and computational approaches are used. It should be noticed that both methods assume the existence of continuum for all calculations.

Recent studies use continuous mechanical approaches for the modeling of nanocomposites and this because modeling at the molecular scale is limited to small time and dimensional scales which limit their uses, especially for engineering applications. Regarding continuous mechanics approaches, the reinforcements are considered homogeneous and isotropic.

\subsection{Analytical formulation}

The overall properties of nanocomposites can be evaluated by a volume average stress and strain fields of the individual constituents.

The rule of mixtures is one of the simplest analytical approaches to predict the elastic properties of the nanocomposites. For a four phase composite material the mathematical expression for composite modulus can be written as :

$$
\begin{gathered}
E=\left(1-V_{f}-V_{N C}-V_{i}\right) E_{m}+V_{f} \cdot E_{f}+V_{i} \cdot E_{i} \\
+V_{N C} \cdot E_{N C}
\end{gathered}
$$

Where $\mathrm{E}, \mathrm{E}_{\mathrm{m}}, \mathrm{E}_{\mathrm{f}}, \mathrm{E}_{\mathrm{i}}$ and $\mathrm{E}_{\mathrm{NC}}$ are the young moduli of the nanocomposite, the matrix, the fiber, the interphase and the $\mathrm{NC}$ respectively and $\mathrm{V}_{\mathrm{f}}, \mathrm{V}_{\mathrm{i}}$ and $\mathrm{V}_{\mathrm{NC}}$ are the volume fractions of the fiber, the interphase and the $\mathrm{NC}$ respectively. The volume fractions of fiber, NC and interphase can be calculated, for a square RVE or "representative volume element", as:

$$
\begin{aligned}
& V_{f}=\frac{\pi r_{f}^{2}}{a^{2}} \\
& V_{N C}=\frac{N_{N C} W_{N C} T h_{N C} L_{N C}}{L a^{2}} \\
& V_{i}=V_{N C}-\frac{N_{N C} \cdot W_{i} \cdot T h_{i} \cdot L_{i}}{L \cdot a^{2}}
\end{aligned}
$$

Where $\mathrm{N}_{\mathrm{NC}}, \mathrm{L}_{\mathrm{NC}}, \mathrm{W}_{\mathrm{NC}}$ and $\mathrm{Th}_{\mathrm{NC}}$ are respectively the number, length, width and thickness of $\mathrm{NC}$ and $\mathrm{r}_{\mathrm{f}}, \mathrm{W}_{\mathrm{i}}, \mathrm{L}$ and a are respectively the radius of fiber, the width of the interphase, the length of the RVE.

The modulus of the interphase differs from that of the matrix and the NCs. It has an intermediate value between $\mathrm{E}_{\mathrm{m}}$ and $\mathrm{E}_{\mathrm{NC}}$ and varies punctually, the equation which gives its punctual value was found by establishing a mathematical model with the following conditions:

$E_{i}=E_{m}$ on the Matrix/Interphase contact surface

$\mathrm{E}_{\mathrm{i}}=\mathrm{E}_{\mathrm{NC}}$ on the Interphase/NC contact surface

One of the methods proposed and gives good agreement with the experimental results $[30,31,32]$ for the calculation of the modulus of elasticity of the interphase is given as follows:

$$
\begin{aligned}
E_{i}(r)=E_{m} \times \frac{r_{i}}{r} & +\left[\frac{r_{i}-r}{r_{i}-r_{N C}}\right]^{n / 2} \\
& \times\left[E_{N C}-E_{m} \times \frac{r_{i}}{r_{N C}}\right]
\end{aligned}
$$

Where, $r=\mathrm{W} / 2$ is a radial coordinate in the interphase region, $\mathrm{n}$ is the interfacial enhancement factor, it depends on the properties of the matrix, NCs and on the interfacial conditions (treatment, additives, etc.).

From eq. 5, we can find the average modulus of elasticity of the interphase as follows:

$$
E_{i}=\frac{1}{r_{i}-r_{N C}} \times \int_{r_{N C}}^{r_{i}} E_{i}(r) d r
$$

The properties of matrix (Epoxy matrix with $10 \%$ of alumina) and fiber are listed in Table1, and those of NC are listed in table 2.

TABLE. I

Fiber and matrix material properties

\begin{tabular}{lll}
\hline \hline & E (GPa) & $v$ \\
\hline Matrix & 6 & 0.3 \\
Palm date fiber [33] & 5 & 0.3 \\
\hline \hline
\end{tabular}

TABLE. II

NanoClay properties [34]

$\begin{array}{ll}\text { Density }\left(\mathrm{Kg} / \mathrm{m}^{3}\right) & 1800 \\ \mathrm{E}_{3}(\mathrm{Gpa}) & 178 \\ \mathrm{v}_{13} & 0,25 \\ \mathrm{G}_{31}(\mathrm{Gpa}) & 70,4 \\ \mathrm{E}_{1}=\mathrm{E}_{2}(\mathrm{Gpa}) & 55 \\ \mathrm{v}_{12} & 0,25\end{array}$

\subsection{Numerical formulation}

Finite Element Method 'FEM' can be used for numerical computation. It also has been used for the prediction of mechanical properties of nanostructured composites.

FEM involves discretization of a RVE for which the elastic solutions lead to determination of stress field. Fig. 4 shows the three possible RVEs for the analysis of NC-based nanocomposites. Cylindrical RVEs are easy to use but they can lead to errors due to ignoring materials not covered by the cylindrical cells. For the present study the square RVE is adopted in both the analytical and numerical computations.
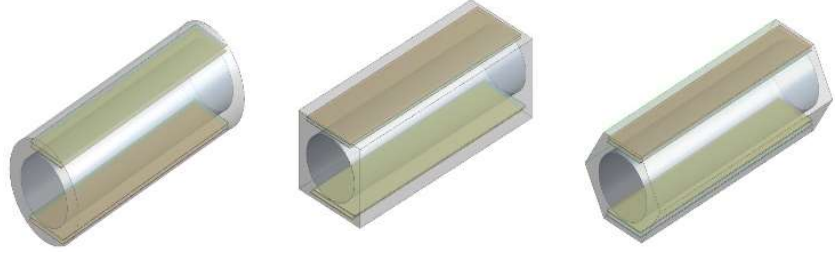

(a)

(b)

(c)

Fig. 4: Three possible RVEs for the analysis of NC-based nanocomposites, (a) Cylindrical RVE; (b) square RVE; and (c) hexagonal RVE. 
As represented in Fig. 4 the palm date fiber is kept in the central part of the representative element while the matrix is reinforced with the nanoclay surrounded by an interphase.

The nanocomposite analysis is conducted using the Ansys software that is one of the few codes that have special capacities to analyze nanocomposite materials. The first step is to define the geometry then the material properties given in Tables 1 and 2. The diameter of the Palm date fiber is $300 \mathrm{~nm}$ and has a length of $500 \mathrm{~nm}$. The matrix has width equal to $400 \mathrm{~nm}$ and a depth equal to $500 \mathrm{~nm}$.

The physical properties of nanoclay are:

$$
\begin{array}{ll}
\text { - } & \text { Width : varies from } 102 \text { to } 353 \mathrm{~nm} \\
\text { - } & \text { Thickness : varies from } 0.59 \text { to } 2.04 \mathrm{~nm} \\
\text { - } & \text { Length }=480 \mathrm{~nm}
\end{array}
$$

The physical properties of interphase are:

$$
\begin{array}{ll}
\text { - } & \text { Width : varies from } 105 \text { to } 356 \mathrm{~nm} \\
\text { - } & \text { Thickness }=1.5 \mathrm{~nm} \\
\text { - } & \text { Length }=483 \mathrm{~nm}
\end{array}
$$

The volume fraction of $\mathrm{NC}$ is set to be $1 \%$ for all calculations.

The mesh is established using the brick elements with refinement for the $\mathrm{NC}$ and the parts of the matrix that surround them Fig. 5. The choice of a brick element is motivated by: on one side brick element is more suitable in a finite element analysis leading to better accuracy, on the other hand the 8 nodes 24 degrees of freedom brick elements leads us to a significant reduction in the number of elements.

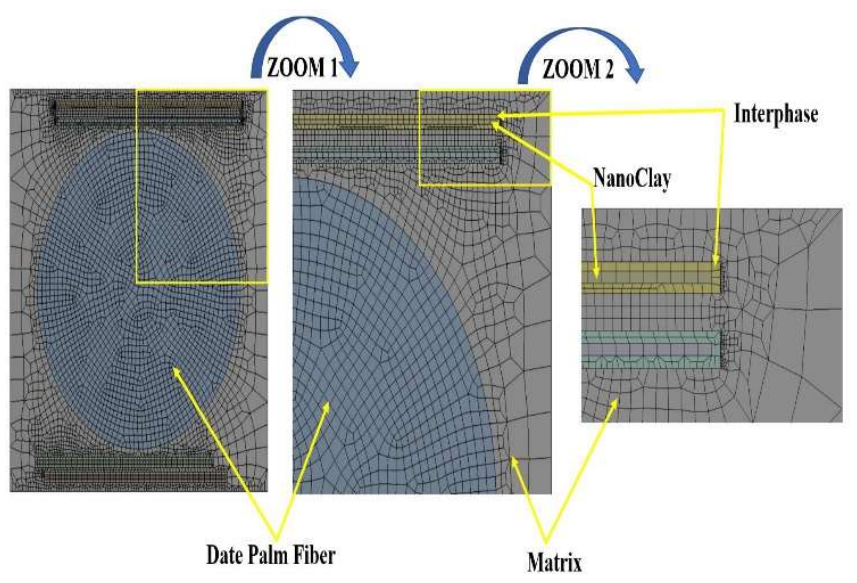

Fig. 5: Meshing of the square RVE containing four NC using brick elements with a zoom on the refined parts.

Depending on nanoclay's thickness, the number of elements varies from $2 \mathrm{E}+05$ to $4 \mathrm{E}+05$ corresponding respectively to $7 \mathrm{E}+05$ to $14.6 \mathrm{E}+05$ nodes. The calculation time varies from $500 \mathrm{~s}$ to up to $3000 \mathrm{~s}$.

To extract the equivalent material constants, a homogenized elasticity model is considered. Solutions can be obtained under axial stretch Fig. 6. The material considered in this study is transversely isotropic and have five independent material constants. The effective material constants are Young's moduli $E_{x}$ and $E_{Z}$, Poisson's ratios $v_{x y}$ and $v_{z x}$ and shear modulus $G_{z x}$. It is to be noticed that the computations were made on the whole of the RVE.

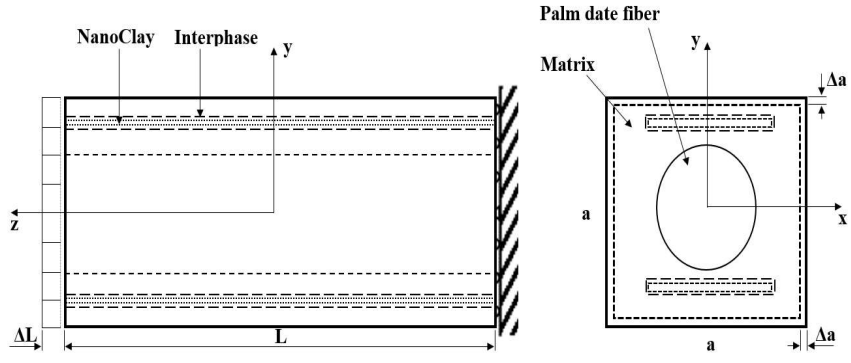

Fig. 6: Square RVE under axial stretch $\Delta \mathrm{L}$

The strain-stress relation relating the normal stresses $\left(\sigma_{\mathrm{x}}, \sigma_{\mathrm{y}}, \sigma_{\mathrm{z}}\right)$ and strains $\left(\varepsilon_{\mathrm{x}}, \varepsilon_{\mathrm{y}}, \varepsilon_{\mathrm{z}}\right)$ for a transversally isotropic material can be written as:

$$
\left[\begin{array}{c}
\varepsilon_{x x} \\
\varepsilon_{y y} \\
\varepsilon_{z z} \\
\varepsilon_{y z} \\
\varepsilon_{z x} \\
\varepsilon_{x y}
\end{array}\right]=\left[\begin{array}{cccccc}
\frac{1}{E_{x}} & -\frac{v_{x y}}{E_{x}} & -\frac{v_{z x}}{E_{z}} & 0 & 0 & 0 \\
-\frac{v_{x y}}{E_{x}} & \frac{1}{E_{x}} & -\frac{v_{z x}}{E_{z}} & 0 & 0 & 0 \\
-\frac{v_{z x}}{E_{z}} & -\frac{v_{z x}}{E_{z}} & \frac{1}{E_{z}} & 0 & 0 & 0 \\
0 & 0 & 0 & \frac{1}{2 G_{z y}} & 0 & 0 \\
0 & 0 & 0 & 0 & \frac{1}{2 G_{z y}} & 0 \\
0 & 0 & 0 & 0 & 0 & \frac{1+v_{x y}}{E_{x}}
\end{array}\right]\left[\begin{array}{c}
\sigma_{x x} \\
\sigma_{y y} \\
\sigma_{z z} \\
\sigma_{y z} \\
\sigma_{z x} \\
\sigma_{x y}
\end{array}\right]
$$

\subsubsection{Square RVE under axial stretch}

The square RVE is embedded on one side and subjected to a displacement $\Delta \mathrm{L}$ on the other side along the $\mathrm{Z}$ axis (Fig. 6).

The stresses and strains are given by: $\sigma_{\mathrm{x}}=\sigma_{\mathrm{y}}=0, \varepsilon_{\mathrm{z}}=\Delta \mathrm{L} / \mathrm{L}$, $\varepsilon_{\mathrm{x}}=2 \Delta \mathrm{a} / \mathrm{a}$ along $\mathrm{x}= \pm \mathrm{a} / 2$

and $\varepsilon_{\mathrm{y}}=2 \Delta \mathrm{a} / \mathrm{a}$ along $\mathrm{y}= \pm \mathrm{a} / 2$

The young's modulus $\mathrm{E}_{\mathrm{z}}$ is then given by :

$$
E_{z}=\frac{\sigma_{\text {ave }}}{\varepsilon_{z}}=\frac{L}{\Delta_{L}} \sigma_{\text {ave }}
$$

where the average value of stress $\sigma_{\mathrm{z}}$ is given by:

$\sigma_{\text {ave }}=\frac{1}{A} \int_{A} \sigma_{z}\left(x, y, \frac{L}{2}\right) d x d y$

where $A$ is the area of the end surface and $\sigma$ ave is calculated from the numerical results.

\section{RESULTS AND DISCUSSIONS}

\section{1- Convergence of the mesh}

The mesh of the nanocomposite is an important step in the digital resolution process. Indeed, for a multiscale material, it is necessary to find an optimal mesh to both have precise results but also to reduce the calculation time. To do this, for each model, a mesh convergence study is necessary in order to obtain the number of elements that allows having an optimal solution. 
Fig. 7 shows that for the nanocomposite based on clay nanoparticles and palm fibers, the modulus of elasticity stabilizes for a number of elements greater than $2 \mathrm{E}+05$.

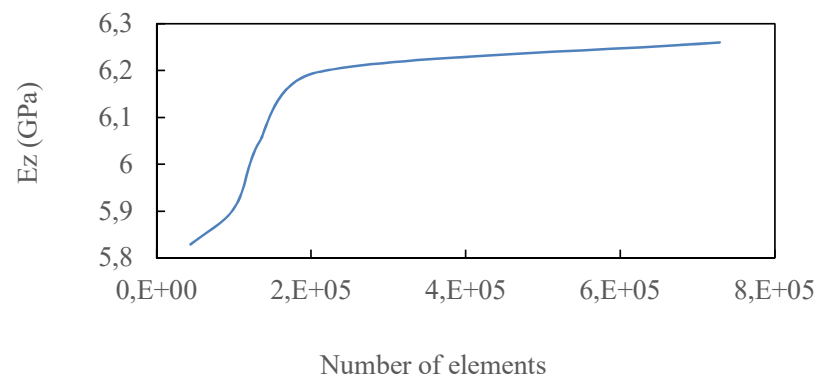

Fig. 7: Meshing convergence with RVE element's number

3.2- Validation of the 3D FEM Model and Effect of the aspect ratio

The results obtained from the 3D MEF model containing NCs are compared to the "ROM" mixture rule which is one of several theoretical models for computing elastic modulus of multi-phase materials. Numerical results are obtained by solving the 3D FEM system using the "ANSYS" simulation software and the equation (8). The analytical results are obtained by the Rule of mixtures ROM Eq. (1).

We see from the results presented in Figure 8 that the 3D FEM model predicts the modulus of elasticity in a similar way to that obtained by ROM with a difference not exceeding $12 \%$ for AR $=50$. This difference decreases for aspect ratio values greater than 50 .

Fig. 8 depicts the effect of AR on the modulus of the composite. The modulus of elasticity can be seen to increase with increasing AR. This is explained by the increase in the Matrix / Nano-reinforcement contact surface (Fig. 9), because the increase in the contact surface generates an increase in the matrix / Nano-reinforcement charge transfer as can be seen from the distribution of constraint in Fig. 10.

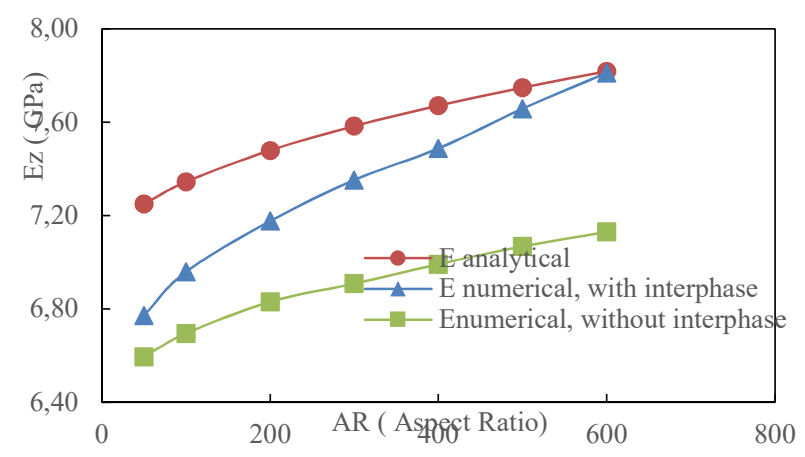

Fig. 8: Evolution of $E_{z}$ with $A R$

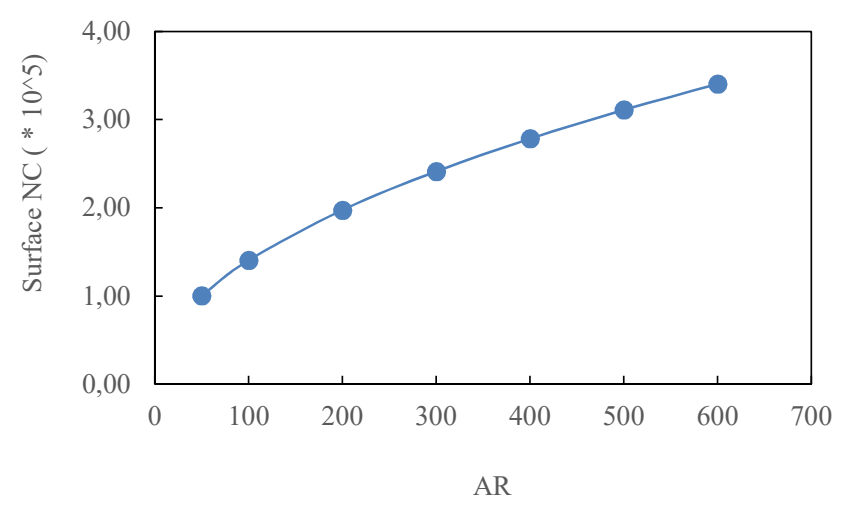

Fig. 9: Evolution of NC's surface with AR

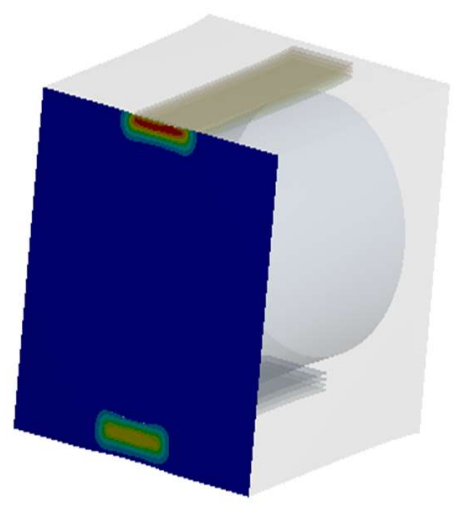

(a)

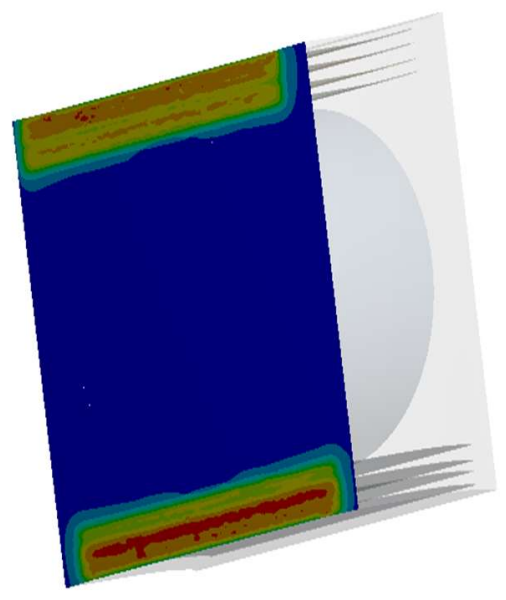

(b)

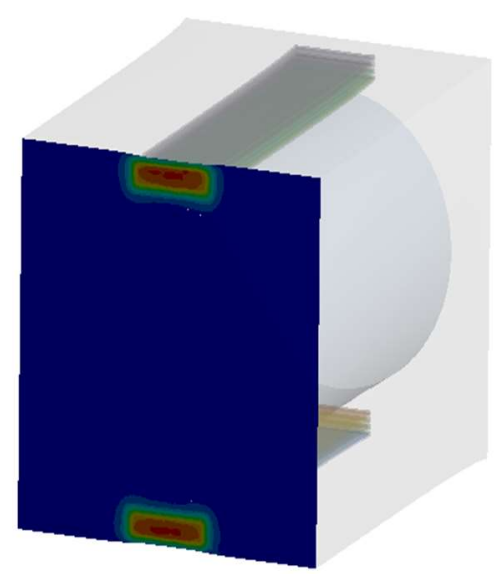



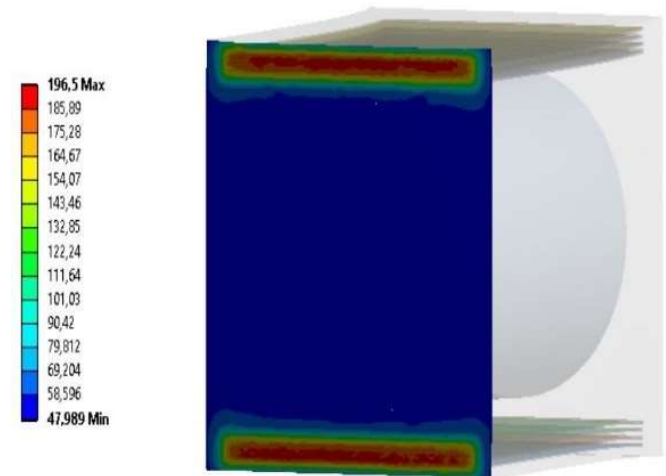

(d)

Fig. 10: Stress plot (MPa) for the surface $Z=500 \mathrm{~nm}$ (a) $A R=50$ without interphase, (b) $\mathrm{AR}=600$ without interphase, (c) $\mathrm{AR}=50$ with interphase, (d) $A R=600$ with interphase

\section{3 effect of $t_{i}$ and $n$ on $E_{i}$}

Fig. 11 depicts the effect of $t_{i}$ and $n$ on the elastic modulus of the interphase. It can be seen that for perfect interfacial conditions characterized by $\mathrm{n}=2$, the interphase modulus decreases with increasing $t_{i}$ (Fig. 11(a)). For imperfect interfacial conditions characterized by $n>2$, the modulus of elasticity of the interphase increases with increasing $t_{i}$ (Fig. 11(c), Fig. 11(d)).

\section{$\mathrm{n}=2$}

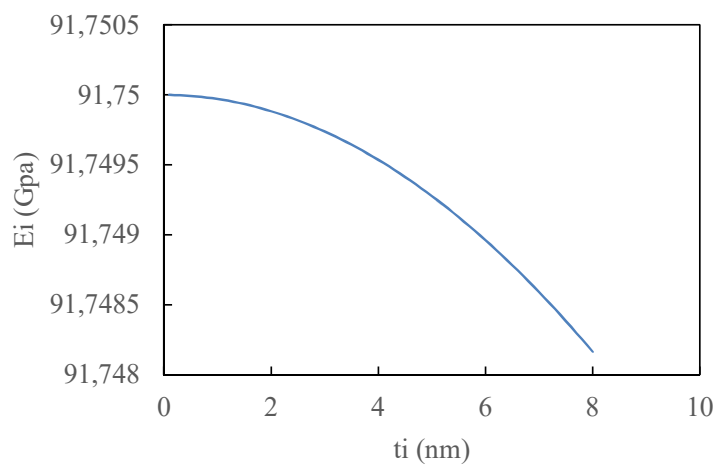

(a)

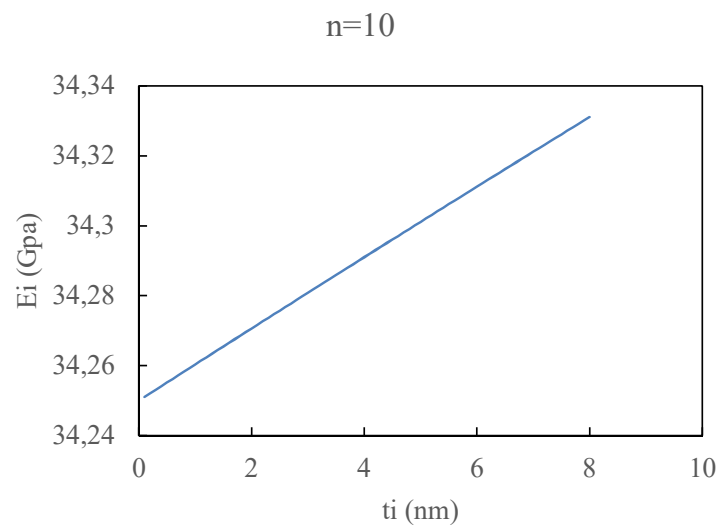

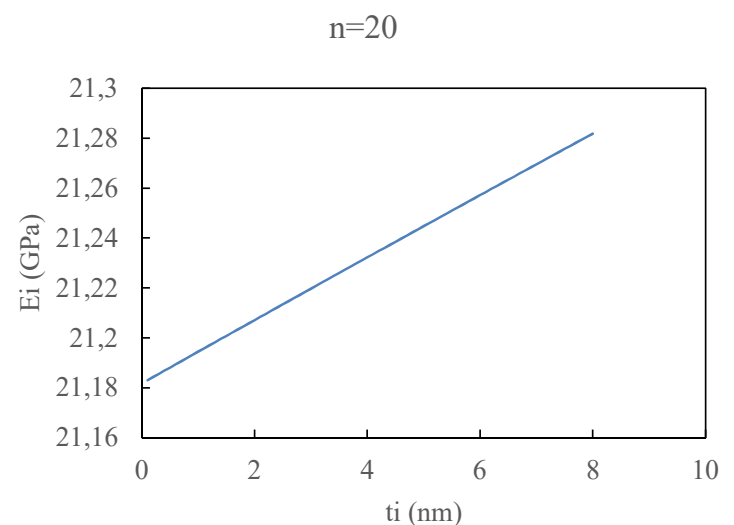

(c)

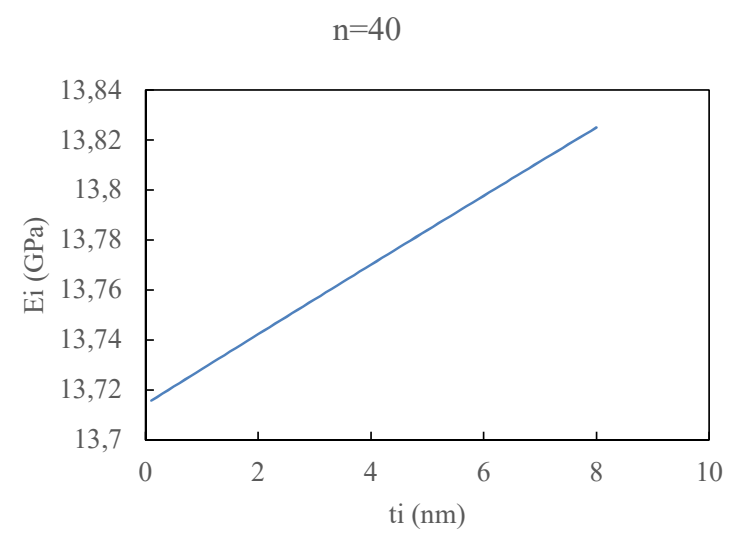

(d)

Fig. 11: Variation of the elastic modulus of the interphase with $n$ and ti (a) $n=2$, (b) $n=10$, (c) $n=20$, (d) $n=40$.

\subsection{Effect of the distance between NC " $d$ "}

Fig. 12 shows the effect of the distance between nano clay particles on the modulus of elasticity of the composite. It can be seen that the greater this inter-particle distance, the greater the modulus of the composite. For $\mathrm{d}=0 \mathrm{~nm}$ there is an agglomeration of the nanoparticles and the contact surface decreases considerably and therefore the charge transfer decreases which leads to a low modulus of elasticity. For a large enough d we have totally exfoliated nanoparticles and give a maximum matrix / nano-reinforcement charge transfer which can be visualized on the stress distribution Fig. 13.

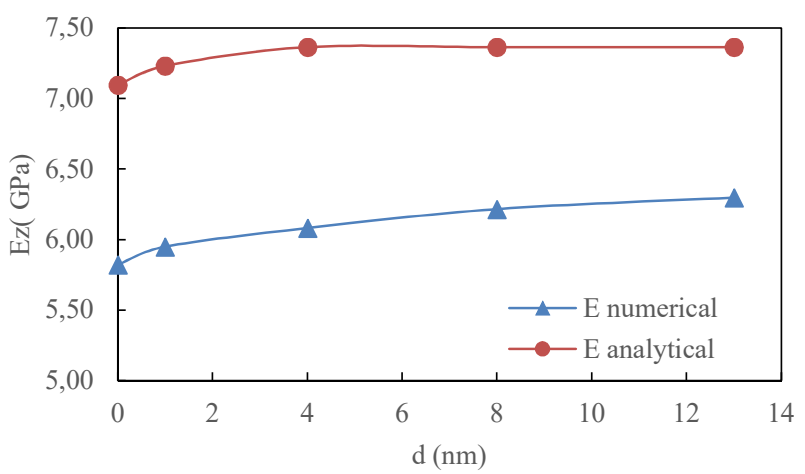

Fig. 12: Evolution of Ez with d 


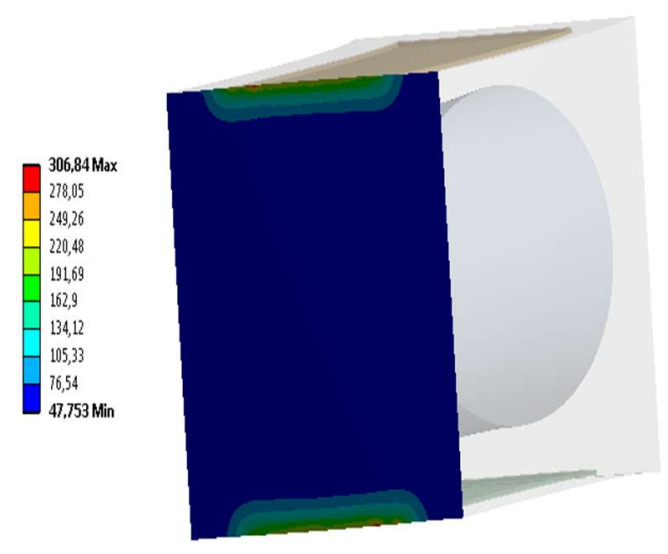

(a)

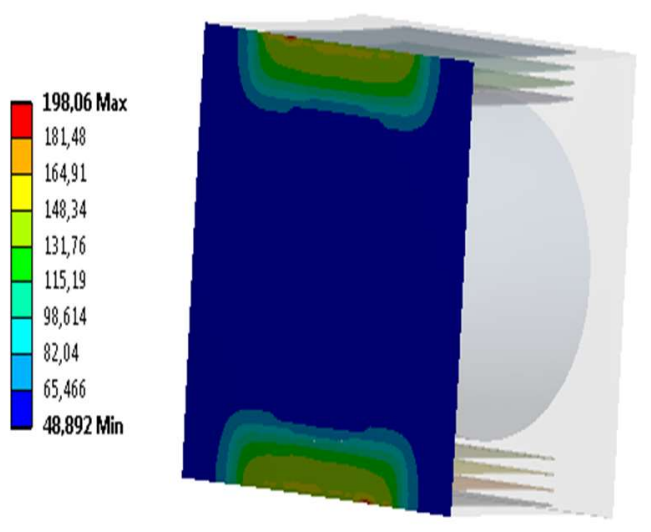

(b)

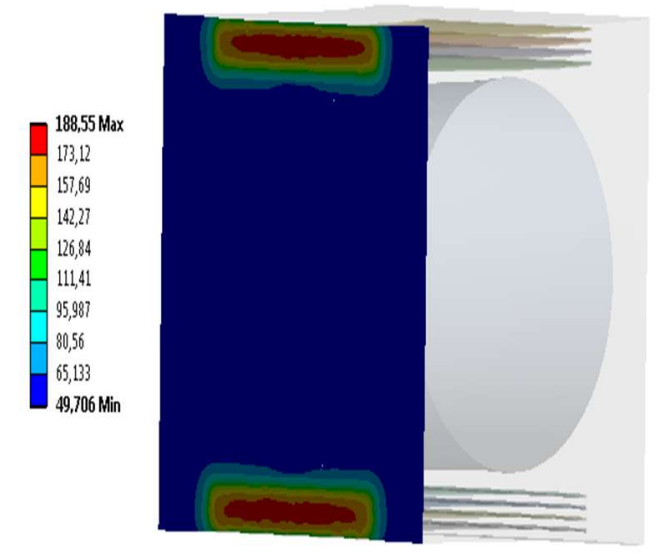

(a)

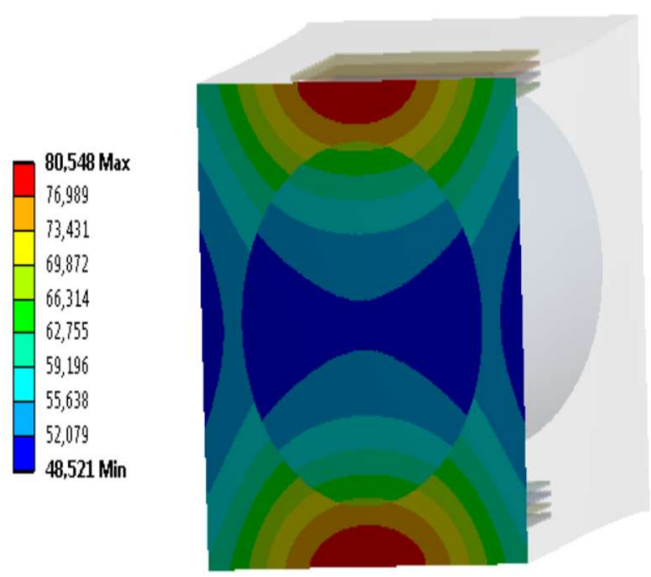

(b)

Fig. 13: Stress plot (MPa) for the surface $z=500 \mathrm{~nm}$ (a) $d=0$ $\mathrm{nm}$, (b) $\mathrm{d}=13 \mathrm{~nm}$.

Fig. 15: Stress plot for the surface $z=500 \mathrm{~nm}$ (a) $D=15 \mathrm{~nm}$, (b) $\mathrm{D}=150 \mathrm{~nm}$.

\subsection{Effect of the distance from charging point "D"}

Fig. 14 depicts the effect of the distance D between the applied load and the nanosheets on the elastic modulus of the composite. We see a decrease in modulus with increasing distance D. This is explained by the existence of losses with respect to the matrix / nano-reinforcement load transfer that can be visualized on the stress distribution in Fig. 15.

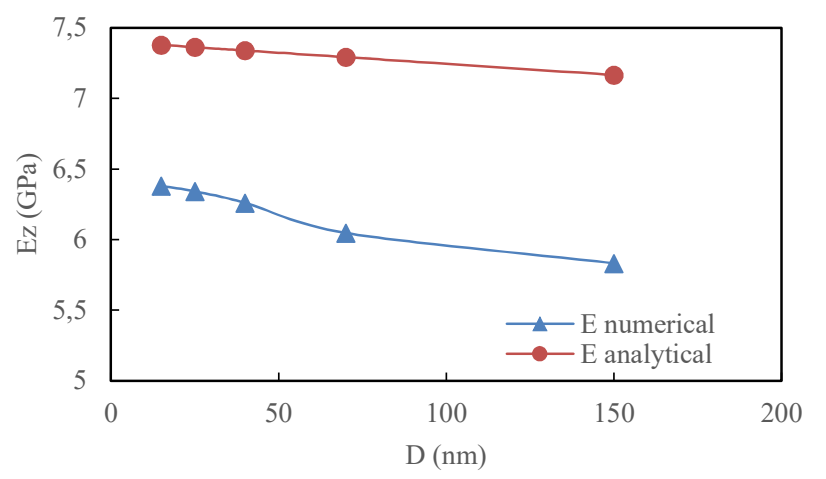

Fig. 14: Evolution of elastic modulus with D

[1] A. G. CUTTER, Development and Characterization of Renewable Resource-based Structural Composite Materials, University of California, San Diego, 2008.

[2] K. MELIANI and S. RECHAK, «Comparative study of biocomposite reinforced with vegetable fiber and based on carbon nanotubes of different corrugated shapes with interphase problem,» COMPOSITE INTERFACES, vol. 27, pp. 161-175, 2019, $10.1080 / 09276440.2019 .1604049$. 
[3] A. M. Bueche, «Filler reinforcement of silicone rubber,» Journal of Polymer Science, vol. 25, no. 1109, pp. 139-149, 1957, 10.1002/pol.1957.1202510902.

[4] B. Kuriakose, S. K. De, S. S. Bhagawan, R. Sivaramkrishnan et S. K. Athithan, «Dynamic mechanical properties of thermoplastic elastomers from polypropylene-natural rubber blend,» Journal of Applied Polymer Science, vol. 32, no. 16, pp. 5509-5521, 1986, 10.1002/app.1986.070320619

[5] M. Sumita, T. Shizuma, K. Miyasaka et K. Ishikawa, «Effect of reducible properties of temperature, rate of strain, and filler content on the tensile yield stress of nylon 6 composites filled with ultrafine particles,» Journal of Macromolecular Science, Part B, vol. 22, no.14, pp. 601-618, 1983, 10.1080/00222348308224779.

[6] P. C LeBaron, Z. Wang et T. J Pinnavaia, «Polymer-layered silicate nanocomposites: an overview,» Applied Clay Science, vol. 15, no. 11, pp. 11-29, 1999, 10.1016/S0169-1317(99)00017-4.

[7] M. Sumita, Y. Tsukumo, K. Miyasaka et K. Ishikawa , «Tensile yield stress of polypropylene composites filled with ultrafine particles,» Journal of Materials Science, vol. 18, pp. 1758-1764, 1983, 10.1007/BF00542072.

[8] P. B. Messersmith et E. P. Giannelis, «Synthesis and Characterization of Layered Silicate-Epoxy Nanocomposites,» Chemistry of Materials, vol. 6, pp. 1719-1725, 1994, 10.1021/cm00046a026.

[9] P. B. Messersmith et E. P. Giannelis, «Synthesis and barrier properties of poly( $\varepsilon$-caprolactone)-layered silicate nanocomposites,» Journal of Polymer Science Part A: Polymer Chemistry, vol. 33, no. 17, pp. 10471057, 1995, 10.1002/pola.1995.080330707.

[10] K. Yano, A. Usuki, A. Okada, T. Kurauchi et O. Kamigaito, «Synthesis and properties of polyimide-clay hybrid,» Journal of Polymer Science Part A: Polymer Chemistry, vol. 31, no. 110, pp. 2493-2498, 1993, 10.1002/pola.1993.080311009.

[11] S. Iijima, «Helical microtubules of graphitic carbon,» Nature, vol. 354, pp. 56-58, 1991, 10.1038/354056a0.

[12] D. T. Colbert et R. E. Smalley, «Past, Present and Future of Fullerene Nanotubes: Buckytubes,» Ösawa E. (eds) Perspectives of Fullerene Nanotechnology, pp. 3-10, 2002, 10.1007/978-94-010-9598-3_1 .

[13] S. Sedaghat, «Synthesis of clay-CNTs nanocomposite,» Journal of Nanostructure in Chemistry, vol. 3, no. 124, 2013, 10.1186/2193-88653-24

[14] S.Pavlidou et C.D.Papaspyrides, «A review on polymer-layered silicate nanocomposites,» Progress in Polymer Science, vol. 33, no. 112, pp. 1119-1198, 2008, 10.1016/j.progpolymsci.2008.07.008.

[15] F. Uddin, «Studies in Finishing Effects of Clay Mineral in Polymers and Synthetic Fibers,» Advances in Materials Science and Engineering, vol. 2013, p. 13, 2013, 10.1155/2013/243515.

[16] G. Xu et F. D.Blum, «Surfactant-enhanced free radical polymerization of styrene in emulsion gels,» Polymer, vol. 49, no. 115, pp. 3233-3238, 2008, 10.1016/j.polymer.2008.05.019.

[17] Y. Zhang, A. Tang, H. Yang et J. Ouyang, «Applications and interfaces of halloysite nanocomposites,» Applied Clay Science, vol. 119, no. 11, pp. 8-17, 2016, 10.1016/j.clay.2015.06.034.

[18] R. Jahanmardi, B. Kangarlou et A. R. Dibazar , «Effects of organically modified nanoclay on cellular morphology, tensile properties, and dimensional stability of flexible polyurethane foams,» vol. 3, no. 182, 2013, 10.1186/2193-8865-3-82

[19] F.L.Nabil, A.Zaidon, M.Jawaid, U.M.K.Anwar, E.S.Bakar, M.T.Paridah, S.M.A.Ridzuan et G.M.Aizat, «Physical and morphological properties of nanoclay in low molecular weight phenol formaldehyde resin by ultrasonication,» International Journal of Adhesion and Adhesives, vol. 62, pp. 124-129, 2015, 10.1016/j.ijadhadh.2015.07.012.

[20] T.D.Fornes et D.R.Paul, «Modeling properties of nylon 6/clay nanocomposites using composite theories,» Polymer, vol. 44, no. 117, pp. 4993-5013, 2003, 10.1016/S0032-3861(03)00471-3.

[21] J. Luo et I. M.Daniel, «Characterization and modeling of mechanical behavior of polymer/clay nanocomposites,» Composites Science and Technology, vol. 63, no. 111, pp. 1607-1616, 2003, 10.1016/S02663538(03)00060-5

[22] G.M. Odegard, T.C. Clancy et T.S.Gates, «Modeling of the mechanical properties of nanoparticle/polymer composites,» Polymer, vol. 46, no. 12, pp. 553-562, 2005, 10.1016/j.polymer.2004.11.022.

[23] K. Hbaieb, Q.X. Wang, Y.H.J. Chia et B. Cotterell, «Modelling stiffness of polymer/clay nanocomposites,» Polymer, vol. 48, no. 13, pp. 901-909, 2007, 10.1016/j.polymer.2006.11.062.
[24] M. Wang, X. Fan, W. Thitsartarn et C. He, «Rheological and mechanical properties of epoxy/clay nanocomposites with enhanced tensile and fracture toughnesses,»P Polymer, vol. 58, no. 110, pp. 43-52, 2015, 10.1016/j.polymer.2014.12.042.

[25] H.W. Wang, H.W. Zhou, R.D. Peng et L. Mishnaevsky, «Nanoreinforced polymer composites: 3D FEM modeling with effective interface concept,» Composites Science and Technology, vol. 71, no. 17, pp. 980-988, 2011, 10.1016/j.compscitech.2011.03.003.

[26] J.K. Kim, D.Z. Wo, L.M. Zhou, H.T. Huang, K.T. Lau et M. Wang, «Finite Element Modelling Epoxy/Clay Nanocomposites,» Key Engineering Materials, vol. 334, pp. 785-788, 2007, 10.4028/www.scientific.net/KEM.334-335.785.

[27] L. Zhu et K.A. Narh, «Numerical simulation of the tensile modulus of nanoclay-filled polymer composites,» Journal of Polymer Science Part B: Polymer Physics, vol. 42, no. 112, pp. 2391-2406, 2004, 10.1002/polb.20112.

[28] Y. Dong et D. Bhattacharyya, «A simple micromechanical approach to predict mechanical behaviour of polypropylene/organoclay nanocomposites based on representative volume element (RVE),» Computational Materials Science, vol. 49, no. 11, pp. 1-8, 2016, 10.1016/j.commatsci.2010.03.049.

[29] P. Valavala et G. Odegard, «Modeling techniques For determination of mechanical properties,» Rev.Adv.Mater.Sc, vol. 9, pp. 34-44, 2005.

[30] M. H. Meybodi, S. S. Samandari et M. Sadighi, «A new approach for prediction of elastic modulus of polymer/nanoclay composites by considering interfacial debonding: Experimental and numerical investigations,» Composites Science and Technology, vol. 117, no. 129, pp. 379-385, 2015, 10.1016/j.compscitech.2015.07.014

[31] S. S. Samandari et A. A. Khatibi, «The Effect of Interphase on the Elastic Modulus of Polymer Based Nanocomposites,» Key Engineering Materials, vol. 312, pp. 199-204, 2006, 10.4028/www.scientific.net/KEM.312.199.

[32] S. S. Samandari et A. A. Khatibi, «Evaluation of elastic modulus of polymer matrix nanocomposites,» Polymer Composites, vol. 28, no. 13, pp. 405-411, 2007, 10.1002/pc.20322 .

[33] S.Abani, F.Hafsi, A.Kriker et A.Bali, «Valorisation of Date Palm Fibres in Sahara Constructions,» Energy Procedia, vol. 74, pp. 289293, 2015, 10.1016/j.egypro.2015.07.608.

[34] M. H. Meybodi, S. S. SAMANDARI et M. SADIGHI, «3D multiscale modeling to predict the elastic modulus of polymer/nanoclay composites considering realistic interphase property,» Composite Interfaces, vol. 23, no. 17, pp. 641-661, 2016, $10.1080 / 09276440.2016 .1166742$.

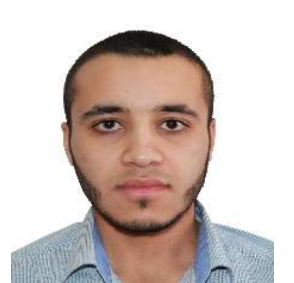

Khaled MELIANI received his mechanical engineering diploma from Ecole Nationale Polytechnique, Algiers and Master's degree in solid mechanics from the same school. He is currently Ph.D student in Ecole Nationale Polytechnique of Algiers. His research fields are biocomposites, nanocomposites, numerical analysis, carbon nanotubes and nanoclays.

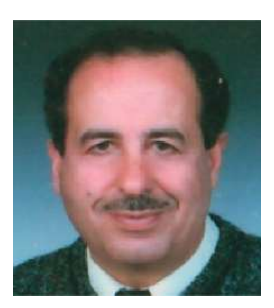

Said RECHAK is a professor at the Ecole Nationale Polytechnique, Algiers. He obtained his degree in Mechanical Engineering from Ecole Nationale Polytechnique in 1980 . He obtained his Master of Science and Ph.D. degrees from the School of Aeronautics and Astronautics at Purdue University, Indiana, USA in 1982 and 1986, respectively. His main research areas are composite materials, numerical modeling by standard, and extended finite element. He opened a new research topic in nonlinear vibration and diagnosis in rotating machinery. He is the author of several scientific papers. 